\section{A CASE OF REPEATED FRACTURE OF BOTH FEMORA RESULTING IN GREAT DEFORMITY.}

By DANIEL BROUGH, M.B., C.M. EDIN., HOUSE SURGEON TO THE DUMFRIKS AND GALLOWAY ROYAL INFIRMARY.

THW following case which has come under my notice is one of interest owing to the peculiar liability which the patient displayed to fracture of the femur on slight injury and the difficulties which must have arisen in the treatment of the various fractures.

The patient was a youth, eighteen years of age, the elder son of a family of two, and had been brought up entirely in the country. The family history was good and showed no hereditary tendency towards fragilitas ossium. The father was the only other member of the family who had had a broken $b$ jne ; this was a fracture of the bones of the forearm, occarring when he was a young man. The younger brother was a healthy lad working on the railway. He had never sustained any fractures and was a bead taller than the patient. Tne patient had never been very robust and his medical adviser informed me that he had suffered from rickets and from tuberculous glands in the neck. He was $4 \mathrm{ft}$. $10 \frac{1}{2}$ in. in height. The first factare occurred when the patient was ten months old. He was lying at the time on his nurse's lap and she, in stooping to raise an article from the floor, must have applied some degree of violence to the patient's leg. The medical man who was called in diagnosed a fracture of the right femur. It was treated with splints for six weeks. I have been unable to obtain any definite information regarding the site of the fracture as the medical attendant is now dead. The patient did not walk until he was twenty.two months old. At three years of age he broke his left thigh-bone for the first time. His mother was leading him by the hand and he stumbled and fell. The amount of violence to the thigh must have been slight, for he fell lightly backwards on to the floor. The bone was broken about the middle and firm union took place in a little over six weeks. E'ght months after the above fracture had healed ke again broke his left femar. He had been attempting to turn a key in the lock of a door. The key came away in his hand and he fell backwards. The fracture was situated at the junction of the upper and middle thirds of the femur. Union took place in nine weeks. At the age of five years, two years after the previous accident, he fell lightly on the floor and broke his left fer ar for the third time. The fracture was situated at the junction of the upper and middle thirds. Union took place in nine weeks. When be was nine years of age he fell backwards and again sustained a fracture of the femur on the left side at the site of the former injury. The fragments were firmly united in eight weeks. At the age of eleven years he met with another slight accident, resulting in disproportionate injary. He slipped and fell backwards on a frosty road. He was found on this occasion to have sustaine $d$ a fracture of the right femur at the junction of the upper and middle thirds. In addition, the right collar bone was broken at the junction of the onter and middle thirds. The clavicle united in four weeks and the femur in eight weeks. The last accident occurred in 1897, when he was seventeen years of age. He fell forwards without much force down three steps and sustained fracture of each femur about the middle. These united firmly in twelve weeks.

Altogether the patient had sustained nine fractures, five being in the left femur, three in the right femur, and one in the right clavicle. In the case of the left femur two of the fractures were situated in the middle of the bone and three at the junction of the upper and middle thirds. In the right femur one occurred in the middle, one at the junction of the upper and middle thirds, while the site of one, occurring in infancy, is unknown. On each occasion the accidert was very slight and the resulting fractures were quite disproportionate to the nature of the fall. As will be seen from the history most of the falls were backwards. The diagnosis of each fracture was easy owing to the amount of displacement which occurred. The injuries were treated by long splint and extension and counter-extension bandages, except on the last occasion when the extension was applied by means of the pulley and weight. Owing to the large number of fractures oecurring at various sites and the difficulties in the way of treatment a great deformity of the femora has resulted. How much deformity and shortening followed each fracture I am unable to say. No doubt each fracture made the succeeding one more difficult to treat. The thighs appeared to be too short for the length of the trunk and legs and a distinct projection could be sten on the outer side of each thigh even when the patient was dressed. The upper half of the left femur was markedly convex outwards. It was in a position of partial flexion and rotation ontwards, the great trochanter being turned backwards. Its rounded lower end formed a marked subcutaneous projection on the anteroexternal surface of the thigh. The lower half met the upper half at an angle and united with it on its postero-internal aspect. The left femur was at least one and a half irches shorter than the right. On the right side the upper half of the femur was abducted

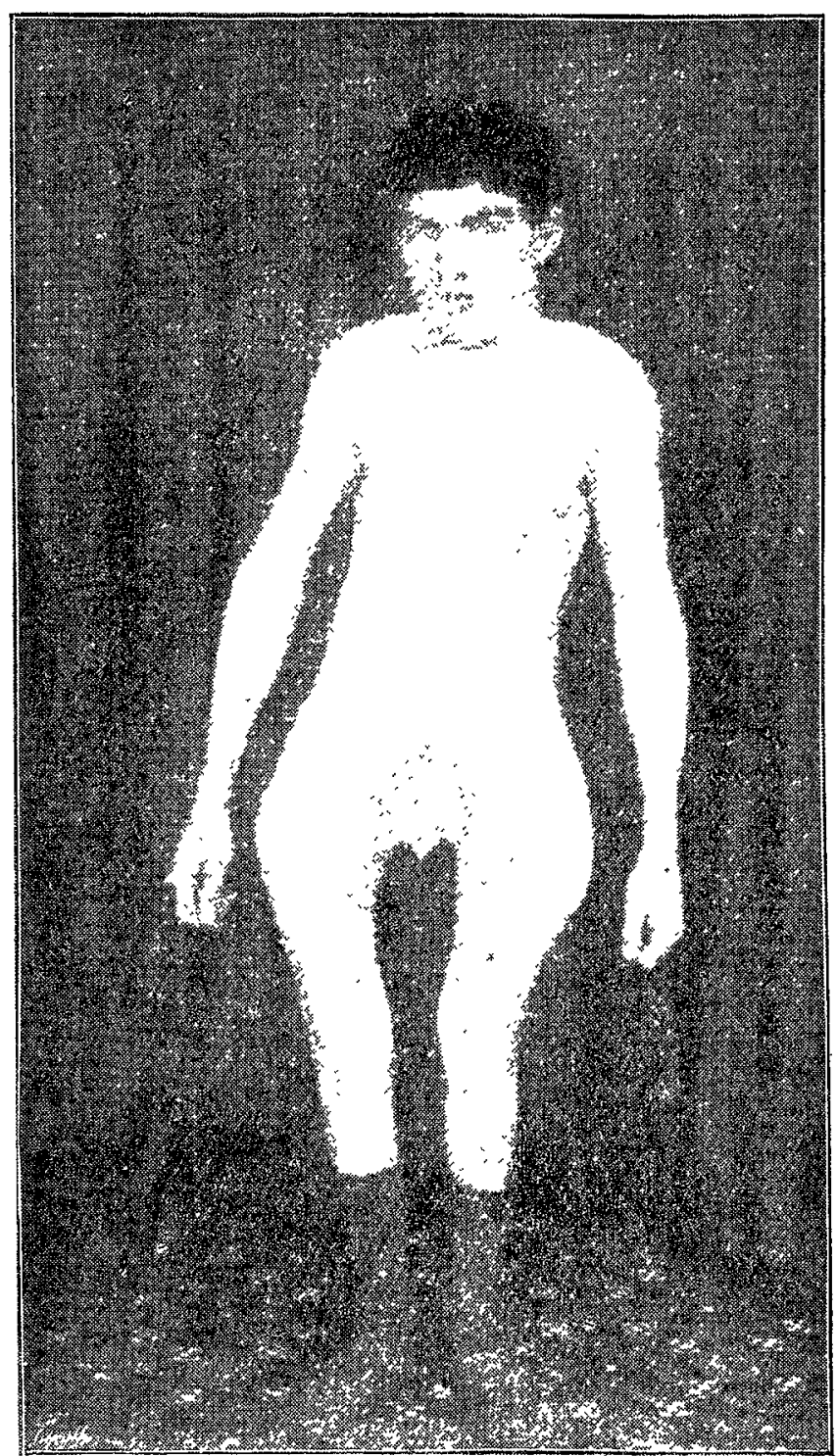

Illustration showing the grave deformity of the femora.

In the right femur it was the 'upper end of the lower half which formed the subcutaneous prominence on the outer surface of the thigh. The lower end of the upper half joined the lower half on its inner surface. There were great thickening and overlapping in both femora at the sites of the various fractures. It was difficult to estimate the amount of shortening which had taken place. It was due both to the overlapping of the ends of the fragments and to the angular deformity of the bones. Probably it was not less than six inches on the left side and it might be more. The clavicle was united in good position. The pelvis was tilted to equalise the length of the lower limbs and there was compensatory curvature of the spine. The patient was markedly pigeon.chested, the sternum being carried far forward. The other bones were normal.

I am indebted to Dr. Reid of Lochmaben for information regarding the injuries, and to Dr. Thomson of Dumfries for permission to publish the case. pumfries. 